Article

\title{
Housing First and Social Integration: A Realistic Aim?
}

\author{
Deborah Quilgars * and Nicholas Pleace \\ Centre for Housing Policy, University of York, York, YO10 5DD, UK; E-Mails: deborah.quilgars@york.ac.uk (D.Q.), \\ nicholas.pleace@york.ac.uk (N.P.) \\ * Corresponding author
}

Submitted: 19 May 2016 | Accepted: 15 July 2016 | Published: 20 October 2016

\begin{abstract}
Housing First is now dominating discussions about how best to respond to homelessness among people with high and complex needs throughout the EU and in several countries within the OECD. Whilst recognised internationally as an effective model in addressing homelessness, little attention has been given as to whether Housing First also assists previously homeless people become more socially integrated into their communities. This paper reviews the available research evidence (utilising a Rapid Evidence Assessment methodology) on the extent to which Housing First services are effective in promoting social integration. Existing evidence suggests Housing First is delivering varying results in respect of social integration, despite some evidence suggesting normalising effects of settled housing on ontological security. The paper argues that a lack of clarity around the mechanisms by which Housing First is designed to deliver 'social integration', coupled with poor measurement, helps explain the inconsistent and sometimes limited results for Housing First services in this area. It concludes that there is a need to look critically at the extent to which Housing First can deliver social integration, moving the debate beyond the successes in housing sustainment and identifying what is needed to enhance people's lives in the longer-term.
\end{abstract}

\section{Keywords}

evaluation; homelessness; Housing First; housing sustainment; social integration

\section{Issue}

This article is part of the issue "Homelessness and Social Inclusion", edited by Isobel Anderson (University of Stirling, UK), Maša Filipovič Hrast (University of Ljubljana, Slovenia) and Joe Finnerty (University College Cork, Ireland).

(C) 2016 by the authors; licensee Cogitatio (Lisbon, Portugal). This article is licensed under a Creative Commons Attribution 4.0 International License (CC BY).

\section{Introduction}

One of the basic prerequisites for social inclusion is having adequate housing from which to live one's life in the community (Anderson, 1993; Pleace, 1998). However, having a house, or home, alone does not in itself guarantee social inclusion. This article investigates the existing, and potential, role of the Housing First model in facilitating the 'social integration' of formerly homeless people. Social integration is a multi-dimensional concept that defies easy definition. Here, a broad focus is adopted, focussing on the extent to which formerly homeless people are able to live, work, learn and participate in their communities to the extent that they wish to, and with as many opportunities as other community members.
The paper begins by charting the rise and significance of Housing First, as well as its limitations, before outlining the present study's methods and findings. A final section discusses the implications of what is known about social integration in Housing First for the future development of services, and methodologies to capture progress, in this area.

Housing First is increasingly being recognised internationally as the most effective model in helping formerly homeless people into settled accommodation. The model has its origins in the Pathways Housing First service which first began to operate in New York in 1990, which aimed to provide independent housing to chronically homeless people, alongside but not conditional on using, intensive mental health and/or drug and alco- 
hol support from specialist teams ${ }^{1}$. An evaluation of the service reported $88 \%$ of clients remained stably housed after five years (Tsemberis, 2010). Other Housing First services, supported by the Federal Government in the USA, have exhibited similarly high levels of housing sustainment rates (Pearson, Locke, Montgomery, \& Buron, 2007). Research suggests Housing First costs no more, or only a little more, than existing services, but can be markedly more effective at ending homelessness than those existing services (Culhane, 2008; Pleace, 2008).

Towards the turn of the decade, this evidence base on Housing First's success in the USA began to influence European-and global-discussions on homelessness. For example, the Jury of the 2010 European Consensus Conference on Homelessness (Jury Committee, 2011) recommended the use of 'housing-led' approaches $^{2}$ to reduce homelessness. Since then, growing numbers of European countries have piloted Housing First (see Pleace, 2016). Two countries, France and Canada, have undertaken experimental evaluations of pilot services, both reporting similar levels of success in housing sustainment as the USA (Goering et al., 2014; Tinland \& Psarra, 2015). A European Housing First project-involving five countries-also reported overall success rates of between $80 \%$ and over $95 \%$ in housing sustainment (Busch-Geertsema, 2013). In addition, there has been evidence of falling 'long term' homelessness among people with high support needs associated with the implementation of the National 'Housing First' strategy in Finland (from 3,600 'long term' homeless people in 2008 to 2,730 in 2011, a fall of 33\%) (Kaakinen, 2012).

Homelessness services which provide temporary accommodation, training in independent living and which require behavioural changes and engagement with health, drug and other support with the aim of making homeless people 'housing ready', have tended to achieve lower levels of success. These services, sometimes called 'staircase' or linear residential treatment (LRT) models, typically assist between $30-50 \%$ of their service users into stable independent accommodation (Pleace, 2008). Significant operational problems have been reported with staircase services, with people leaving due to strict rules or becoming 'stuck' on particular steps on the 'staircase' to independent living that these services require someone to take to make them 'housing ready' (Pleace, 2008; Sahlin, 2005). In contrast, Housing First provides immediate or near immediate access to housing, alongside support to maintain that housing. Housing First also emphasises respect for individuals, giving them choices about using mental health, drug and alcohol and other services and some choice over where to live, within the resources available. Guidance on Housing First in Europe, closely follows the original US model and states that Housing First has eight core principles (Pleace, 2016, p. 12):
- Housing is a human right

- Choice and control for service users

- Separation of housing and treatment

- Recovery orientation

- Harm reduction

- Active engagement without coercion

- Person-centred planning

- Flexible support that is available for as long as is required

The growing, and strong (Woodhall-Melnik \& Dunn, 2015), evidence base on the effectiveness of the Housing First model suggests that, resources and political will permitting, it may be possible to achieve lasting reductions in sustained and recurrent homelessness among people with very high support needs, including those with both severe mental illness and problematic use of drugs and alcohol (Pleace, 2016).

However, there are outstanding questions for Housing First services that centre on what happens after a chronically homeless person has been successfully rehoused by a Housing First service. Evidence reviews have indicated somewhat mixed results from Housing First in terms of improvements on the mental and physical health for formerly and potentially chronically homeless people, and have argued for additional research to conclusively determine its impact (Johnson, Parkinson, \& Parsell, 2012; Pleace \& Quilgars, 2013; WoodhallMelnik \& Dunn, 2015). In addition, the subject of this paper-the extent to which Housing First services can, and should, promote social integration for formerly and potentially chronically homeless people-has received little attention.

Housing First seeks to promote social integration through the delivery and sustainment of settled, independent housing. There is an emphasis on ordinary housing, which is scattered across ordinary neighbourhoods, as the means by which social integration is delivered. This view is expressed strongly by advocates of the idea that any Housing First service model must have very high fidelity with the original Pathways model (Greenwood, Stefancic, Tsemberis, \& Busch-Geertsema, 2013). Through facilitating formerly homeless people to live in the same way as everyone else, Housing First seeks to promote social integration by the provision of a 'base' in the normal world from which ontological security will result and social integration can start to take place (Padgett, 2007). This overall approach is summarised in the 'Pathways' Housing First manual:

"Pathways Housing First seeks to help clients integrate into their community as fully as possible, and the housing component plays an important role in achieving this goal. The likelihood of stigma associated with being a member of a psychiatric treatment

\footnotetext{
${ }^{1}$ An ACT (Assertive Community Treatment) team for chronically homeless people with very high support needs and an Intensive Case Management (ICM) team for chronically homeless people with high needs.

${ }^{2}$ Approaches that provide housing but do not necessarily replicate the Housing First model.
} 
programme is reduced, because the programme is not visible on site, and clients live in normal settings. Clients frequently interact with their neighbours at the local market, Laundromat, movie theatre, coffee shop or park. The clients share the same community and socialization opportunities as their non-disabled neighbours." (Tsemberis, 2010, pp. 53-54)

Whilst the original USA Housing First model did not expect specific support structures, further than the built-in support already in the model, to be put into place to foster social integration, some newer non-USA models have incorporated interventions directed at increasing participation in the local community. For example, in Canada, Housing First is delivering a number of specific Employment, Training and Education (ETE) programmes (Goering et al., 2014).

Some single-site Housing First services have also been developed. These have been criticised on the basis that the absence of normal housing, in a normal community, surrounded by normal people, 'prevents' social integration (Tsemberis, 2011). Others have argued that single site models can act as source of social support, creating communities of support, and that, it is possible to socially integrate people into their extended communities (Pleace, Knutagård, Culhane, \& Granfelt, 2016). This review, however, focused solely on scattered Housing First models.

To date, two key issues have been raised regarding Housing First and social integration. Firstly, there is the question about what social integration means for formerly homeless people with high support needs. Here there are questions around balancing expectations of what a socially integrated citizen should look like, something that is linked to specific expectations about behaviour (Hansen Löfstrand \& Juhila, 2012). Second, there are a set of questions around how social integration is delivered, with some criticism centred on the vagueness of the mechanisms by which ordinary housing in ordinary communities delivers social integration (Johnson et al., 2012). This paper critically reviews what is known about the extent to which social integration can be achieved by Housing First.

\section{Methods}

This paper is based on an international Rapid Evidence Assessment (REA). The REA method streamlines traditional systematic review methods in order to synthesize evidence within a short timeframe. An REA can be an effective way of identifying social policy lessons where information may be scattered across different research disciplines, in different formats and where resources available are limited (Thomas, Newman, \& Oliver, 2013). Unlike a systematic review, the REA uses broader criteria for the assessment of evidence, including research and studies that do not necessarily meet the highest possible standards. This can be useful in an emerging subject such as Housing First where the number of experimental and quasi-experimental studies is relatively small, but where there is a large body of observational research that can add to the available evidence.

This REA covered service evaluations and research on Housing First and other housing based services for homeless people. The review was international in scope, although in practice, relevant studies originated from Europe (9 countries), USA, Australia and Canada. Papers were included published in English as well as articles in the French language (translated for the research team). The review included studies undertaken since 1990 when the Housing First concept was first introduced. Papers were selected which covered one or more aspects of social integration for homeless people (see definition below). Research was not excluded utilising quality criteria (due to the relative infancy of the topic), rather researchers reported on the robustness of studies.

Search strategies were designed with a trained information specialist in the Centre for Reviews and Dissemination (CRD) at the University of York. The original search was conducted by the information specialist in January 2013, across 15 social sciences and medical databases, identifying 1,258 references for review. Searches were re-run by the researchers up to May 2016, and a further 100 papers were reviewed. In addition, presentations from five Housing First/homelessness conferences attended by the researchers were also reviewed. Full details on the search strategies, and overall methodology, can be found at Pleace and Quilgars (2013).

Data was synthesised under identified headings (see below). A number of caveats need to be noted about this analysis. Crucially, it was not possible to take account of the different political, institutional and societal country contexts which may explain differences in levels of effectiveness (Doling, 1997). It was also not possible to evaluate the extent to which the interventions maintained fidelity to the original Housing First model (Pleace, 2016). In terms of understanding 'social integration' and related terms, there is also a high likelihood that the terms will be understood differently across different cultural contexts (Quilgars et al., 2009).

\subsection{Defining Social Integration}

Social integration is a complex, multi-dimensional concept. There is no one agreed definition and, like social inclusion, definitions are contested (Hedetoft, 2013; Huxley, 2015). This review started with a broad definition of social integration - the extent to which formerly homeless people are able to live, work, learn and participate in their communities as they wish to, and with as many opportunities as other members of the wider community. This is similar to the World Bank definition of social inclusion which refers to the process of improving the terms for individuals and groups to take part in society (see Huxley, 2015). Reflecting this starting point, the search strategy included the following key terms: 
- Social integration/inclusion/participation

- Community integration/integration/participation

- Neighbourhood integration/inclusion/participation

- Economic integration/inclusion/participation

The study undertook a review of definitions of 'social integration' within the retrieved literature, and drew on wider debates on social inclusion, to inform the thematic groupings of the research findings. We identified four main areas of interest.

Firstly, most definitions were centred on 'joining' or participating in community activities, with much of this debate originating in the mental health field. Wong and Solomon (2002) developed what was acknowledged as a 'leading model' (Gulcur, Tsemberis, Stefancic, \& Greenwood, 2007) of 'community integration' for people with mental health problems. This definition focused on three main types of integration, firstly, physical integration (participation in activities, and use goods and services); secondly, social integration (social interaction with community members and social network); and thirdly, psychological integration (feeling part of the community and exercising influence).

Subsequently, Ware, Hopper, Tugenberg, Dickey and Fisher (2007) argued for a redefinition of community integration to better capture social dimensions, focusing on the 'capabilities approach' that looks at what people can do and be in everyday life, and how their competencies and opportunities are shaped by social environments. They argue that this definition requires social change (for example, welfare reform) as well as looking at people's individual quality of life.

Some discussion has also centred on the meaning of 'community'. Sociologists have long recognised that communities do not only develop around 'place', but also from shared interests and identities (Means \& Evans, 2012). Arguments have been made that long term homelessness, while removed from mainstream social and economic life, also provides social support via a homeless 'community', to which a sense of 'belonging' develops. While, the idea that there is a distinctive homeless 'culture' is not well evidenced (O'Sullivan, 2008), the idea that chronic homelessness means a 'total' lack of any form of social integration needs to be treated with caution.

Communities can also be dispersed. There is evidence that dispersed networks of family, friends and colleagues, maintained using information and communication technologies, are an increasingly commonplace aspect of social integration in economically developed societies (Savage, Bagnall, \& Longhurst, 2005). Exclusion, for chronically homeless people, might therefore exist in terms of connectedness to other homeless people, the wider community living around them, but also due to limited access to dispersed social networks, and social media technologies.

Secondly, some studies were explicitly or implicitly concerned with formerly homeless people 'passing' or being accepted in society, that is not being judged as different from those around them, counteracting a risk of experiencing stigmatisation and prejudice (Goffman, 1963). One set of barriers to formerly homeless people's social inclusion are the cultural, political and mass media images of homelessness that emphasise individual pathology - a supposed refusal to accept or abide by the conventions of mainstream society-and combinations of mental ill health and drug/alcohol problems as the 'causes' of homelessness (Hansen Löfstrand \& Juhila, 2012; O'Sullivan, 2008). For example, landlords may assume that support needs related to mental health problems and/or drug and alcohol problems may result in anti-social behaviour (Pleace, Teller, \& Quilgars, 2011).

Thirdly, studies also discussed wider social inclusion issues. The context of most homeless people's lives is one of social exclusion, which includes problematic access to income and work, alongside community and social relations (Gordon et al., 2000; Pleace, 1998). An existing body of research (Zuvekas \& Hill, 2000) suggests that formerly homeless people with high support needs are often very distant from the point of securing and maintaining paid work. Recently, there has been an increasing focus on education, training and economic participation of homeless as a route to social integration (Bretherton \& Pleace, 2015).

Finally, a limited amount of discussion (and research) focused on 'voting' or 'political participation'. The concept of 'citizenship', that there is a relationship between a citizen and society, that society provides civil and political rights and (to varying degrees) social protection, in return for political and economic participation is near universal in democratic countries. However, a growing 'disconnection' between citizens and formal political participation is seen as a social problem in many EU member states (Bouget \& Brovelli, 2010).

\section{Housing First and Social Integration: Findings}

\subsection{Joining (Community Participation)}

Studies have varied tremendously in their definitions and measurement of community participation. Below, we review findings under the main foci of study, however categories overlap.

\subsubsection{Community and Social Links}

In the Housing First Europe observational study (BuschGeertsema, 2013), in four of the five projects, the projects supported participants to access community resources, such as sports and recreation facilities, libraries, local cafes and restaurants, community events as well as health, drug and alcohol community programmes. However, the extent to which participants engaged in community activities differed considerably within any one project. For example, in Lisbon, almost half of the 45 interviewees reported having met people at a restaurant or cafe in the last month, one in seven had gone to a li- 
brary or participated in sports/recreation activities, but less than one out of ten had participated in a community event or attended a movie or concert. The small numbers and lack of comparison/control groups with local population make interpretation of the results difficult.

Tsai, Mares and Rosenheck (2012) tracked 550 chronically homeless adults with mental health problems across an 11-site USA Collaborative Initiative to Help End Chronic Homelessness ( $\mathrm{ClCH}$ ) for one year after rehousing into permanent housing. They recorded a small but statistically significant increase in community participation (examining activities over the 'last two weeks') over the period, including increases in number of service users who used a bank; visited a grocery store; visited close friends, relatives or neighbours; went to a shopping centre or similar. However, there was no increase in activity in many other areas including use of public transport, libraries, and cultural events. Social support also did not significantly change over time. Importantly, any changes in social integration were not found to be significant following changes in clinical symptoms, suggesting that the degree to which someone experiences social integration may be partly mediated by symptom changes.

An earlier study including 183 Housing First participants in New York examined community integration ${ }^{3}$ after four years rehousing, compared to Treatment As Usual (TAU) (Gulcur et al., 2007). This study found the Housing First project was statistically more likely to predict social integration (on two measures: satisfaction with social support and number of social network members) than TAU services. However, other aspects of community integration were not predicted by Housing First (nor by other programme domains like mental health treatment). Nonetheless, the authors concluded:

"Considering that our study found that a normalised residential arrangement was the only significant predictor of social integration, this would suggest that services may need to shift towards the provision of housing that most closely resembles that of the general population, for example independent scattersite housing in the community. Additionally, housing agencies should encourage consumers to exercise choice regarding their lives, especially since this increased sense of autonomy leads to a greater sense of belonging and well-being. The Housing First model, with its emphasis on independent housing, consumer choice and empowerment, may therefore be particularly well suited for enhancing community integration." (p. 224)

A four year randomised controlled trial (RCT) for a housing-led Australian Journey to Social Inclusion (J2SI) programme also reported only modest improvements in social inclusion (Johnson, Kuehnle, Parkinson, Sesa, \& Tseng, 2014). Using two newly developed measures of self-rated 'social acceptance' and 'social support', they found a consistent, but modest, improvement on both measures over time, but no significant difference between a housing-led model (similar but not identical to Housing First) and TAU. However, the trend was in a positive direction and the final J2SI participants did record their highest scores at the end of the four years.

A 2015 observational study of Housing First pilots in England reported some positive evidence around social integration with neighbourhoods and with reestablishing links with family. Of a sample of 60 Housing First service users, 21 (25\%) reported monthly, weekly or daily contact with family a year prior to using Housing First, rising to 30 (50\%) when asked about their current contact (while being supported by a Housing First service). However, rates of contact with family, while improving, remained low overall (Bretherton \& Pleace, 2015).

\subsubsection{Quality of Life}

A RCT of the Housing First 'Chez Soi' Project in Canada included an examination of social outcomes, over two years, for 2,148 individuals randomly allocated to Housing First (HF) and TAU facilities (Goering et al., 2014). It utilised two scales: participant reported Quality of Life Index (QOLI 20) and researcher completed Multnomah Community Ability Scale (MCAS). The study documented immediate increases and more gradual continuing improvements for participants in both Housing First and TAU groups, and a small but statistically significantly difference in favour of Housing First services. The largest treatment effect in community functioning, which relates to 'passing' below, was in 'behaviour' (including cooperation with providers, substance use and impulse control); and also some effects related to improvements in 'social skills' (ability and willingness to interact with others). On quality of life, the biggest difference between the two groups was for 'living' (home and neighbourhood), with a small difference in perceived safety and finances-with the authors suggesting that these benefits were related to the housing component of HF. However, whilst participant satisfaction with social lives/family relationships improved in both groups, this was about the same for both HF and TAU groups.

The French Housing First randomised controlled trial also included a Quality of Life Index (Index SQoL) and reported a significant difference between Housing First and TAU at the 12-month point-again both groups showed an improvement, but this was statistically higher in the Housing First group (Tinland \& Psarra, 2015).

\subsubsection{Ontological Security}

There is some evidence that people using Housing First who are settled into scattered housing, start to exhibit what can be called 'normalised' behaviour as a result of ontological security, arising from having a settled

\footnotetext{
${ }^{3}$ Using Wong and Solomon's model, with an added domain of 'independence/self-actualisation'.
} 
home. Recent research in London has suggested that even homeless people with a prolonged history of homelessness and high support needs, start to behave in a very similar or identical way to 'housed' people once they are resettled into scattered housing (Bretherton \& Pleace, 2015). American qualitative research shows how rehoused people (in Housing First and other scatter housing) report increased feelings of privacy, independence and freedom to pursue interests (Yanos, Barrow, \& Tsemberis, 2004).

Qualitative work in Canada (Goering et al., 2014) highlighted, that 'the quality of participant's daily lives changed from being survival orientated to being 'more secure', 'peaceful', and 'less stuck' which enabled them to move forward with their lives' (p. 28). In addition, the People with Lived Experience Caucus for the Canadian Chez Soi Project in Toronto undertook a detailed qualitative analysis of community integration at the 18month follow-up point for both Housing First and TAU clients (Coltman et al., 2015). Housing was seen as offering people more than a place to live-providing security, safety, feelings of self-worth and 'a symbol of them being a functional member of society' (p. 47), including a place to entertain friends and family, and the neighbourhood offers community spaces and social encounters. However, respondents also stressed that poor housing and/or neighbourhoods could make it harder to connect to friends/family and could also make people feel unsafe. It also highlighted how community activities could both be experienced as enriching and/or as unfulfilling and stressful.

Other small scale, qualitative work in Sweden (Knutagard \& Kristiansen, 2013) and Norway (Andig \& Kare Hummelvoll, 2015) have reported promising results in terms of tenants feeling empowered to move forward in their lives, with some improvements in social networks and a sense of hopefulness.

\subsection{Passing (Community Acceptance)}

Existing evidence suggests that Housing First projects may impact positively on rates of anti-social behaviour, but that where rates are high, the model is only likely to partially tackle the issue. The Housing First Europe observational study (Busch-Geertsema, 2013) found that neighbourhood conflicts were rare in three projects, and were usually successfully resolved via the work of the project. For example, in Lisbon, the Housing First project brought together all partners to find a solution in the rare cases that an issue was presented. In Glasgow, staff also acted as intermediaries with relevant parties to avoid evictions in almost all cases (Johnsen \& Fitzpatrick, 2013).

However, in contrast, the Discus Housing First project in Amsterdam encountered high rates of nuisance behaviour, with nuisance being associated with 41 of the 100 Housing First apartments. However, Amsterdam was part of a wider strategy that was partially targeted on reducing nuisance behaviour among street using homeless people: it is therefore possible that the service was aimed at those with challenging behaviour to a greater extent than the other Housing First Europe projects.

An observational examination of nine Housing First pilot services in England found some evidence of reductions in anti-social behaviour, but like the Netherlands service, rates of anti-social behaviour remained quite high. Among 60 service users, 78\% reported involvement in anti-social behaviour a year prior to using Housing First, compared to $53 \%$ when asked about current behaviour one year on (Bretherton \& Pleace, 2015).

The only study focused on recidivism examined single site Housing First services (Clifasefi, Malone, \& Collins, 2012). The number of days that people spent in prison (mean of 41 to 18 days) and bookings (mean of 3.43 to 1.49) fell when they were using Housing First services. The study found that the vast majority of convictions were 'misdemeanours', likely to be associated with sustained and recurrent homelessness. Earlier research has found a positive relationship between entering accommodation with support and reductions in criminality, meaning the positive effect may not be confined to Housing First models (Culhane, Hadley, \& Metraux, 2002).

\subsection{Working (Economic Participation)}

Available evidence does not suggest that Housing First services generate high levels of employment amongst participants, although some increase in job searching, training or volunteering may be more likely. Results from the Housing First Europe study found that very few participants were in paid work (Busch-Geertsema, 2013), a result similar to the findings of a study of nine pilot Housing First services in England (Bretherton \& Pleace, 2015). However, participation levels in training, education and other activities were more mixed. For example, only $13 \%$ of Copenhagen participants undertook any form of activity. However, $28 \%$ of participants were engaged in voluntary work in Amsterdam, and 32\% of Lisbon Housing First participants were involved in job site training, educational courses or other meaningful activities. Qualitative work on the Glasgow project indicates that employment is often seen as a long-term goal by most service users (and staff) (Johnsen \& Fitzpatrick, 2013).

The large study of Housing First outcomes in the USA (550 homeless people across 11 sites) found no significant differences in levels of employment among participants after one year, and a slight decrease in the number of people volunteering (Tsai et al., 2012). However, the study did find that Housing First service users who were participating in the community were also more likely to be working (and have better social supports). This finding may suggest that having a settled home may act as a 'gateway' to social inclusion for some people, however it is also possible that the association is in the other direction, with work facilitating better social supports and social inclusion. 
Australian work on the J2SI model, which included an integrated training and skills development programme, reported significant increases in economic participation rates (those either looking for, or in, paid work) during the pilot stage from $30 \%$ to $51 \%$ at the 18 -month stage, a much higher rate than for TAU (Johnson et al., 2014). However, they also reported that this participation rate fell back to lower than the baseline $(21 \%)$ once the project closed. Moreover, only five people were in paid employment at 36 months (in both the housing-led and control group), and no-one at the 48-month point one year after the main project had closed. They highlighted the casual nature of most work available and how outcomes were shaped by 'exogenous factors beyond the control of individuals or services' (p. 21).

The Canadian At Home/Chez Soi Housing First services are delivering a number of specific Employment, Training and Education (ETE) programmes, for example: the Moncton 'At Home' Services which provides full-time vocational support to help people identify work opportunities, and a community employment project where participants are employed by the project to provide cleaning, packing and moving services. The evaluation did not report on economic outcomes per se, however 'new social roles' were an important factor in positive life courses across sites (along with stable housing, positive social contacts, and reduced substance abuse) (Goering et al., 2014).

\subsection{Voting (Political Participation)}

There is little evidence on which to base a discussion of the role of Housing First services in promoting political participation. The logic of Housing First as a means to enable political participation again centres on the security of a home forming the base from which community participation, economic activity and then political participation can be built. The findings of one study supports this idea-in the recent USA CICH study of 550 Housing First service users - there was an increase over one year from a minority of $21 \%$, to $31 \%$, of service users saying they intended to vote (Tsai et al., 2012).

\section{Discussion}

The evidence base on social integration and Housing First up until 2013 was described as 'limited' (Pleace \& Quilgars, 2013, p. 4) and 'inconclusive' (Woodhall-Melnik \& Dunn, 2015, p. 8). In the last two years, a number of additional studies have been published, providing some further evidence, however overall the body of work in this area remains under-developed. This has both implications for future research and practice on Housing First.

Firstly, in terms of research, the review found that most studies utilised different definitions-and measures-of social integration. It appeared that most researchers 'tacked on' an examination of some aspects of social integration, but it was rarely the main focus of any study. The review found that most attention has been placed on 'community participation', in particular around engagement with local community resources. However, there was a lack of clarification on the distinction between social networks and access and use of community resources. Quality of Life measures were the most robust methodologically but had least relevance to community participation. 'Ontological security' was also discussed but not clearly measured in studies. A number of studies were concerned with 'community acceptance', indicating some possible impact, but this was difficult to assess due to a lack of comparability with other services. Studies on 'economic participation' were also underdeveloped, whilst data on voting was virtually missing altogether. Further, some studies were longitudinal (utilising different time periods), others took a snap shot in time. Overall, the nature of the research makes comparing findings across problematic-without taking account of considerable country specific differences (Quilgars et al., 2009). In the mental health field, Gulcur et al. (2007) concluded that the concept of community integration still needed a 'clearly articulated conceptual framework'. A key conclusion from this review is that Housing First researchers, working with other social scientists, need to develop better measures of social integration that can be utilised consistently in future evaluations.

The review highlighted a number of other methodological gaps. Qualitative work in Canada (Coltman et al., 2015) highlighted the importance of the many small interactions by which people establish relationships, feelings of self-worth and hopefulness, and the significance of pets. Some dimensions of social integration such as friendship, feelings of worth and hopefulness remain underexplored due to difficulty in measuring them. Generally, service user perspectives on the meaning of social integration need further development (Gulcur et al., 2007). More work is also needed to explore possible neighbourhood effects (Yanos, Felton, Tsemberis, \& Frye, 2007). No studies have examined the role of dispersed networks on social integration. Research has demonstrated that someone can be highly socially networked and not speak to their neighbours or the community around them (Savage et al., 2005). Finally, even with all the above questions answered, we have little idea as to how long it may take for someone to become socially integrated. One study found that mental health consumers were more integrated the longer they lived in the area (Yanos, Stefancic, \& Tsemberis, 2012). Finally, there is also a lack of clarity as to what point, or factors need to interact, to conclude that someone is socially integrated.

Whilst methodological challenges limit the strength of any conclusions on Housing First and social integration, the review highlighted a number of possible implications for the development and delivery of Housing First services. The housing component of Housing First is often seen as the key to achieving social integration, in terms of living in normal community settings and sharing the same socialisation and community opportunities as oth- 
ers. Whilst this review suggests that Housing First may have some impact on feelings of 'ontological security', the evidence is far from conclusive. Hopper (2012) has questioned this idea that social integration will automatically flow from living in the community in ordinary housing and whether too much burden is being placed on the capacity, will and initiative of formerly homeless individuals to 'make themselves' socially integrated. The same arguments have been made by Johnson et al. (2012) when critically reviewing the suitability of Housing First for Australia.

Perhaps partly in response to the recognition that housing is not enough to support formerly homeless people, some newer models of Housing First have developed more specifically targeted services that focus on aspects of social integration, particularly in the area of learning, training and finding jobs. This review has shown relatively weak effects from these services to date, although some increase in positive activities at the point that people are supported. Broader community integration issues may be addressed by Housing First support workers as part of a holistic response to people's needs, however services rarely have a specific focus on this. Considerable research has indicated that formerly homeless people may often be socially isolated when they have been housed or re-housed (Busch-Geertsema, 2005; Crane, Coward, \& Warnes, 2011). A number of low intensity support service models have been used for other client groups to enhance community participation and social networks, such as befriending services (Quilgars, 2000). A few Housing First services are using peer mentors (Johnsen \& Fitzpatrick, 2013). Evidence suggests that such services are not easy to deliver but there is potential for positive impacts on people's lives (Bretherton \& Pleace, 2016; Quilgars, Johnsen, Pleace, Beecham, \& Bonin, 2011); good practice in this area may be worth investigating in greater detail for Housing First.

A more philosophical and ethical point also arises from the review. When considering the situation of formerly homeless people, it is important to consider the extent to which it is a 'social norm' to be a member of a balanced, cohesive and socially interactive community (Savage et al., 2005). Hansen Löfstrand and Juhila (2012), argue that Housing First services still define the behaviour of homeless people as something that needs 'correcting' (albeit relatively slowly and flexibly), echoing the underlying logic of staircase services seeking to install and reinforce 'self-governing' behaviour that will make people using Housing First 'responsible choice makers'. This raises the idea of one set of standards for poor and marginalised groups with respect to what is regarded as social integration and another, rather more flexible interpretation for more affluent groups, whose economic integration is arguably taken as a sufficient representation of 'social integration' (Burrows, 2013; Lupton \& Tunstall, 2008).

Finally, the relatively limited impacts of Housing First on social integration, suggest that we may not be analysing the issue through the appropriate lens. Increas- ingly, prominent European homelessness researchers (Busch-Geertsema, 2013; Johnson et al., 2014) are arguing that it is not realistic to expect homelessness services to deliver 'total' solutions to homelessness. The founder of the original Pathways Housing First project in New York has noted the following in relation to what it may be reasonable to expect a Housing First service to deliver:

"It is important here to revisit the mission of HF [Housing First]: it is to end homelessness for people with complex needs. Of course, the ideal outcome would be to end homelessness and solve all problems related to mental health, addiction, and social exclusion, but we are not there yet...beyond a program intervention [a Housing First service], larger shifts in social contexts and policies are needed to achieve greater success in alleviating poverty, facilitating recovery, and promoting social inclusion." (Tsemberis, 2012)

Ultimately, Housing First practitioners may need to consider how they can influence broader local and national policies to tackle problems of social exclusion in the wider society.

\section{Conclusion}

This review suggests that we might only be able to expect current Housing First models to deliver modest impacts in the area of social integration for formerly homeless people. Further conceptual and practical developments in this area may be required to make more progress. As well as developing a stronger conceptual framework, a re-examination of some of the key components of the Housing First model might offer a way forward on social integration issues in the future. Firstly, choice and control, and the person-centred approach, which are at the centre of the philosophy, should put user views on the meaning of social integration and any assistance needed with this to the forefront of debates in this area. Secondly, Housing First support is offered for as long as is required-social integration needs to be viewed within a longer time frame than has so far been the case. Finally, the respect for common humanity that underpins a response to deliver housing immediately to homeless people who have too often been judged and penalised for their situation, could arguably be taken one step further towards a rights based agenda. With the case for housing sustainment via Housing First all but won, much like disability campaigners, advocates of Housing First could usefully now begin to identify and challenge societal barriers and structures that limit the futures of formerly homeless people in their respective communities.

\section{Acknowledgments}

Our thanks go to Lisa Stirk at the Centre for Reviews and Dissemination at the University of York for conducting the original searches for the review. The review 
was funded by DIHAL, France, and commissioned via FEANTSA.

\section{Conflict of Interest}

The authors declare no conflict of interests.

\section{References}

Anderson, I. (1993). Housing policy and street homelessness in Britain. Housing Studies, 8(1), 17-28.

Andig, E., \& Kare Hummelvoll, J. (2015). From struggling to survive to a life based on values and choices: Firstperson experiences of participating in a Norwegian Housing First project. Nordic Journal of Social Research, 6, 167-183.

Bouget, D., \& Brovelli, G. (2010). Citizenship, social welfare system and social policies in France. European Societies, 4(2), 161-184.

Bretherton, J., \& Pleace, N. (2015). Housing First in England. York: University of York.

Bretherton, J., \& Pleace, N. (2016). Crisis skylight: Journeys to progression: Second interim report of the University of York evaluation. London: Crisis.

Burrows, R. (2013). The new gilded ghettos: The geodemographics of the super-rich. Sociology, 41(5), 885899.

Busch-Geertsema, V. (2005). Does re-housing lead to reintegration? Follow-up studies of re-housed homeless people. Innovation, 18(2), 202-226.

Busch-Geertsema, V. (2013). Housing First Europe: Final report. Retrieved from http://www.socialstyr elsen.dk/housingfirsteurope/copy4_of_FinalReport HousingFirstEurope.pdf

Clifasefi, S. L., Malone, D. K., \& Collins, S. E. (2012). Exposure to project-based Housing First is associated with reduced jail time and bookings. International Journal of Drug Policy. doi:10.1016/j.drugpo.2012.10.002

Coltman, L., Gapka, S., Harriott, D., Koo, M., Reid, J., \& Zsager, A. (2015). Understanding community integration in a Housing-First approach: Toronto At Home/Chez Soi community-bases research. Intersectionalities, 4(2), 39-50.

Crane, M., Coward, S., \& Warnes, A. M. (2011). Moves to independent living: Single homeless people's experiences and the outcomes of resettlement. Sheffield: Sheffield Institute for Studies on Ageing, University of Sheffield.

Culhane, D. P. (2008). The cost of homelessness: A perspective from the United States. European Journal of Homelessness, 2(1), 97-114.

Culhane, D. P., Hadley, T., \& Metraux, S. (2002). Public service reductions associated with placement of homeless persons with severe mental illness in supportive housing. Housing Policy Debate, 13(1), 107-163.

Doling, J. (1997). Comparative housing policy. Basingstoke: MacMillan.

Goering, P., Veldhuizen, S., Watson, A., Adair, C., Koop,
B., Latimer, E., . . . Aubry, T. (2014). National At Home/Chez Soi Final Report. Calgary: Mental Health Commission of Canada.

Goffman, E. (1963). Stigma. London: Penguin.

Gordon, D., Townsend, P., Levitas, R., Patsios, D., Middleton, S., Ashworth, K., . . . Williams, J. (2000). Poverty and social exclusion in Britain. York: Joseph Rowntree Foundation.

Greenwood, R. M., Stefancic, A., Tsemberis, S., \& BuschGeertsema, V. (2013). Implementations of Housing First in Europe: Successes and challenges in maintaining model fidelity. American Journal of Psychiatric Rehabilitation, 16(4), 290-312.

Gulcur, L., Tsemberis, S., Stefancic, A., \& Greenwood, R. M. (2007). Community integration of adults with psychiatric disabilities and histories of homelessness. Community Mental Health Journal, 43(3), 211-228.

Hansen Löfstrand, C., \& Juhila, K. (2012) The discourse of consumer choice in the Pathways Housing First model. European Journal of Homelessness, 6(2), 47-68.

Hedetoft, U. (2013) Social inclusion: Inaugural editorial. Social Inclusion, 1(1), 1-2.

Hopper, K. (2012). The counter reformation that failed? A commentary on the mixed legacy of supported housing. Psychiatric Services, 63(5), 461-463.

Huxley, P. (2015). Introduction to 'Indicators and Measurement of Social Inclusion'. Social Inclusion, 3(4), 50-51.

Johnsen, S., \& Fitzpatrick, S. (2013). Glasgow Housing First: Final report for the Housing First Europe project. Glasgow: Turning Point.

Johnson, G., Parkinson, S., \& Parsell, C. (2012). Policy shift or program drift? Implementing Housing First in Australia, AHURI Final Report No. 184. Melbourne: Australian Housing and Urban Research Institute.

Johnson, G., Kuehnle, D., Parkinson, S., Sesa, S., \& Tseng, Y.-P. (2014). Sustaining exits from long-term homelessness: A randomised controlled trial examining the 48 month social outcomes from the Journey to Social Inclusion pilot program. St Kilda: Sacred Heart Mission.

Jury Committee. (2011). European Consensus Conference on Homelessness: Policy recommendations of the Jury. Belgium: European Commission.

Kaakinen, J. (2012). Long term perspectives: From Housing First to ending homelessness. Paper presented at Housing First: A Key Element of European Homelessness Strategies, French Permanent Representation, Brussels.

Knutagard, M., \& Kristiansen, A. (2013). Not by the book: The emergence and translation of Housing First in Sweden. European Journal of Homelessness, 7(1), 93-115.

Lupton, R., \& Tunstall, R. (2008). Neighbourhood regeneration through mixed communities: A 'social justice dilemma'? Journal of Education Policy, 23(2), 105117.

Means, R., \& Evans, S. (2012). Communities of place 
and communities of interest? An exploration of their changing role in later life. Ageing and Society, 32(8), 1300-1318.

O'Sullivan, E. (2008). Pathways through homelessness: Theoretical and policy implications. In J. Doherty \& B. Edgar (Eds.), In my caravan, I feel like Superman: Essays in honour of Henk Meert. Brussels: FEANTSA.

Padgett, D. (2007). There's no place like (a) home: Ontological security among persons with a serious mental illness in the United States. Social Science and Medicine, 64, 1925-1936.

Pearson, C. L., Locke, G., Montgomery, A. E., \& Buron, L. (2007). The applicability of Housing First models to homeless persons with serious mental illness. Washington, DC: Department of Housing and Urban Development.

Pleace, N. (1998). Single homelessness as social exclusion: The unique and the extreme. Social Policy and Administration, 32(1), 46-59.

Pleace, N. (2008). Effective services for substance misuse and homelessness in Scotland: Evidence from an international review. Edinburgh: Scottish Government.

Pleace, N. (2016). Housing First guide: Europe. York: University of York.

Pleace, N., Knutagård, M., Culhane, D. P., \& Granfelt, R. (2016). The strategic response to homelessness in Finland. In N. Nichols \& C. Doberstein (Eds.), Exploring effective systems responses to homelessness (pp. 426-442). Toronto: The Homeless Hub. Retrieved from http://homelesshub.ca/sites/default/ files/4.2\%20Pleace.pdf

Pleace, N., \& Quilgars, D. (2013). Improving health and social integration through Housing First: A review. Brussels: DIHAL/FEANTSA.

Pleace, N., Teller, N., \& Quilgars, D. (2011). Social housing allocation and homelessness. Brussels: FEANTSA.

Quilgars, D. (2000). Low intensity support services: A systematic review of effectiveness. York: Joseph Rowntree Foundation.

Quilgars, D., Elsinga, M., Jones, A., Toussaint, J., Ruonavaara, H., \& Naumanen, P. (2009). Inside qualitative, cross-national research: Making methods transparent in a EU housing study. International Journal of Social Research Methodology, 12(1), 19-31.

Quilgars, D., Johnsen, S., Pleace, N., Beecham, J., \& Bonin, E. (2011). Supporting independence? Evaluation of the Teenage Parent Supported Housing pilot. London: Department for Education.

Sahlin, I. (2005). The staircase of transition: Survival through failure. Innovation, 18(2), 115-136.

Savage, M., Bagnall, G., \& Longhurst, B. (2005). Globalization and belonging. London: Sage.
Thomas, J., Newman, M., \& Oliver, S. (2013). Rapid evidence assessments of research to inform social policy: Taking stock and moving forward. Evidence \& Policy: A Journal of Research, Debate and Practice, 9(1), 5-27.

Tinland, A., \& Psarra, C. (2015). Housing First: Lessons from France. Presentation at the Institute of Global Homelessness Seminar, Chicago.

Tsai, J., Mares, A. S. \& Rosenheck, R. A. (2012). Does housing chronically homeless adults lead to social integration? Psychiatric Services, 63(5), 427-434.

Tsemberis, S. (2010). Housing First: Ending homelessness, promoting recovery and reducing costs. In I. Gould Ellen \& B. O'Flaherty (Eds.), How to house the homeless. New York: Russell Sage Foundation.

Tsemberis, S. (2011) Observations and recommendations on Finland's "Name on The Door Project" from a Housing First perspective. Retrieved from http:// www.housingrst./les/1242/Tsemberis_2011_-_Obser vations_and_Recommendations.pdf

Ware, N. C., Hopper, K., Tugenberg, T., Dickey, B., \& Fisher, D. (2007). Connectedness and citizenship: Redefining social integration. Psychiatric Services, 58(4), 469-474.

Wong, Y. L. I., \& Solomon, P. L. (2002). Community integration of persons with psychiatric disabilities in supportive independent housing: A conceptual model and methodological considerations. Mental Health Services Research, 4(1), 13-28.

Woodhall-Melnik, J., \& Dunn, J. R. (2015). A systematic review of outcomes associated with participation in Housing First programs. Housing Studies. doi:10.1080/02673037.2015.1080816

Yanos, P. T., Barrow, S., \& Tsemberis, S. (2004). Community integration in the early phase of housing among homeless persons diagnosed with severe mental illness: Successes and challenges. Community Mental Health Journal, 40(2), 133-150.

Yanos, P. T., Felton, B. J., Tsemberis, S., \& Frye, V. A. (2007). Exploring the role of housing type, neighbourhood characteristics, and lifestyle factors in the community integration of formerly homeless persons diagnosed with mental illness. Journal of Mental Health, 16(6), 703-717.

Yanos, P. T., Stefancic, A., \& Tsemberis, S. (2012). Objective community integration of mental health consumers living in supported housing and of others in the community. Psychiatric Services, 63(5), 438-444.

Zuvekas, S. H., \& Hill, S. C. (2000). Income and employment among homeless people: The role of mental health. The Journal of Mental Health Policy and Economics, 3(3), 153-163. 


\section{About the Authors}

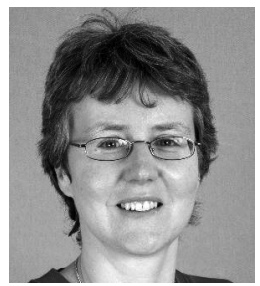

Deborah Quilgars, Senior Research Fellow at the Centre for Housing Policy, University of York, has over twenty-five years' research experience in the area of homelessness and housing and support services. She is an expert on youth homelessness and has directed research examining the effectiveness of services for young homeless people, teenage parents at risk of homelessness, homeless families, homeless ex-offenders and most recently homeless veterans with support needs. Deborah is a member of the Women's Homelessness in Europe Network (WHEN).

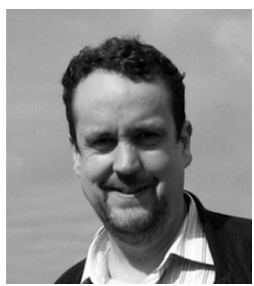

Nicholas Pleace, Senior Research Fellow at the Centre for Housing Policy, University of York, is an international expert on homelessness. He specialises in evaluations of homelessness services and strategies, including innovative approaches to tackling unemployment and improving social supports for (formerly) homeless people. He has a particular interest in Housing First. Nicholas also works for the European Observatory on Homelessness, under the Fédération Européenne d'Associations Nationales Travaillant avec les Sans-Abri (FEANTSA), the European federation of homelessness organizations. 